\title{
Candida albicans adherence to a human oesophageal cell line
}

\author{
Elena Enache, Tara Eskandari, Leticia Borja, Elsa Wadsworth, \\ Becky Hoxter and Richard Calderone
}

Department of

Microbiology and Immunology, Georgetown

University School of

Medicine, 3900 Reservoir

Road NW, Washington, DC

20007, USA
Author for correspondence: Richard Calderone. Tel: +1202687 1137. Fax: +1 2026871800.

e-mail : rcalde01@gumedlib.dml.georgetown.edu
The oesophageal epithelium appears to be one of the primary cell targets of Candida albicans in AIDS patients. To study this interaction, we have established an in vitro adherence assay using a human epithelial oesophageal cell line (HET1-A). When yeast cells were grown in $500 \mathrm{mM}$ D-galactose, adherence increased significantly over cultures prepared in $500 \mathrm{mM}$ D-glucose. In addition to HET1-A cells, adherence of the organism grown in D-galactose to human buccal epithelial cells and a murine alveolar macrophage cell line was also higher. Adherence of yeast cells to HET1-A cells was partially inhibited in the presence of $D$-glucosamine or $N$-acetyl-D-glucosamine, but not with $D$ mannose, D-glucose, L-fucose or D-galactose. Attachment to HET1-A cells was studied using scanning and transmission electron microscopy. Partial phagocytosis of adhering yeast cells was observed occasionally within the first 90 min following infection, as evidenced by the formation of HET1-A pseudopodia in instances of close contact with yeast cells. The influence of $D$ galactose on cell surface proteins was studied by analysing $\beta$-mercaptoethanolextracted proteins from yeast cells grown in either $500 \mathrm{mM}$ D-galactose or Dglucose. From D-galactose-grown cells only, a glycoprotein of approximately $190 \mathrm{kDa}$ was observed in Aurodye-stained SDS-PAGE gels and in Western blots using an immunoglobulin fraction (IgG) prepared from sera of rabbits infected with the organism. These studies demonstrate that $C$. albicans adheres to human oesophageal cells and may utilize cell surface proteins whose synthesis is nutritionally regulated.

Keywords: adhesin, oesophagus cells, Candida albicans

\section{INTRODUCTION}

Adherence of Candida albicans to mammalian cells appears to be essential for the establishment of an infection by the organism (Calderone \& Braun, 1991; Cutler, 1991; Calderone \& Wadsworth, 1993). There is considerable evidence that cell surface glycoproteins of the organism recognize both the extracellular matrix proteins of endothelial cells as well as epithelial fucosyl- or glucosaminecontaining glycosides or glycosphingolipids (Critchley \& Douglas, 1987a; Tosh \& Douglas, 1992; Yu et al., 1994). Thus, it would appear that $C$. albicans is able to recognize a variety of host cell receptors through the use of an as yet unknown number of cell surface adhesins. This ob-

Abbreviations: $\beta$-ME, $\beta$-mercaptoethanol; HBEC, human buccal epithelial cells; HBSS, Hanks' Balanced Salt Solution. servation is not surprising when one considers the variety of host cells and tissues which can be colonized and invaded by the organism.

The AIDS epidemic has resulted in an increased number of patients with oral, vaginal and oesophageal candidiasis (Georgopapadakou \& Walsh, 1994; Klein et al., 1984), yet little is known about the recognition of oesophageal epithelial cells by $C$. albicans. We have initiated studies of this nature using an SV-40-transformed human oesophageal cell line (HET1-A) established by Stoner et al. (1991). When transformed, these cells are not tumourigenic and retain an epithelial cell morphology and the typical array of epithelial cell surface antigens.

McCourtie \& Douglas (1981) observed that when yeast cells were incubated in $500 \mathrm{mM}$ D-galactose, adherence of the organism to human buccal epithelial cells (HBEC) was significantly increased compared to yeast cells from 
cultures grown in equimolar concentrations of D-glucose. Additionally, they reported that the cell surface of galactose-grown yeast cells appeared fibrillar, and the yield of adhesin from culture supernatants was greater (McCourtie \& Douglas, 1984). In this report, we have investigated the influence of carbon sources on the adherence of $C$, albicans to HET1-A cells and a murine alveolar macrophage cell line (MH-S) in addition to HBEC. The attachment of yeast cells to HET1-A cells was also studied by electron microscopy. Finally, we performed preliminary studies on the comparison of cell surface proteins from C. albicans grown on D-galactose or on D-glucose.

\section{METHODS}

Candida strains and growth conditions. C. albicans strain 4918 has been described previously (Hoberg et al., 1986; Linehan $e t$ al., 1988; Calderone et al., 1988). C. albicans 4918-2, a spontaneous, cerulenin-resistant strain, was derived from $C$. albicans 4918 (Hoberg et al., 1986). Strain A9 was originally isolated from an AIDS patient (Whelan et al., 1990). For adherence assays, each strain was propagated from frozen stocks on Sabouraud Dextrose Agar slants (Difco) at room temperature for $48 \mathrm{~h}$ and subsequently recultured overnight at room temperature on yeast-peptone (YP) agar (Difco) supplemented with either $500 \mathrm{mM}$ D-galactose or $500 \mathrm{mM} \mathrm{D}$-glucose. Cells were collected in Hanks' Balanced Salt Solution containing magnesium and calcium (HBSS; Gibco BRL) and washed twice with HBSS. For adherence assays, yeast cells were standardized to approximately $1 \times 10^{7}$ cells $\mathrm{ml}^{-1}$.

Propagation of HET1-A cells. HET1-A cells were cultured in serum-free tissue culture medium (EPM2; Biological Research Faculty \& Facility) in polystyrene flasks $\left(250 \mathrm{ml}, 75 \mathrm{~cm}^{2}\right.$; Becton Dickinson). Cultures were maintained in monolayers initially seeded with approximately $1-2 \times 10^{6}$ HET1-A cells obtained from a nearly confluent culture, and collected by treatment of monolayers (approximately $5-6 \times 10^{6}$ cells) with $1 \mathrm{ml}$ polyvinylpyrrolidone, EGTA and trypsin (Biological Research Faculty \& Facility). The HET1-A cells were washed with tissue culture medium (EPM2) and standardized as described above. On a monthly basis, frozen stocks of HET1-A cells were used to replace existing cultures and were propagated as described above.

HBEC and murine alveolar macrophages. HBEC from healthy volunteers were collected in $\mathrm{PBS}(0.02 \mathrm{M} \mathrm{NaCl} ; 0.15 \mathrm{M}$ sodium phosphate) $(0.2 \mathrm{M}, \mathrm{pH} 7 \cdot 2)$, washed two to three times with PBS and standardized to $5 \times 10^{5}$ cells $\mathrm{ml}^{-1}$. The alveolar macrophage cell line (MH-S; Sankaran \& Herscowitz, 1995) was maintained as a continuous culture in RPMI 1640 medium, (Gibco BRL) containing 10\% (v/v) foetal calf serum. MH-S cells were collected by trypsinization, washed in RPMI 1640, standardized to $1 \times 10^{6} \mathrm{cells} \mathrm{m}^{-1}$ and added in a total of $2 \mathrm{ml}$ to sterile glass coverslips in 6-well tissue culture dishes (Corning). The monolayers were used for adherence assays $48 \mathrm{~h}$ after seeding.

Adherence assays. HET1-A cells were seeded in 6-well tissue culture dishes (Corning) at a density of $5 \times 10^{5}$ cells per well in a total of $2 \mathrm{ml}$ EPM 2 medium. After $48 \mathrm{~h}$, the monolayers were washed in HBSS and infected with $1 \times 10^{7}$ yeast cells in HBSS. Cultures were incubated for different times $(0-3 \mathrm{~h})$ and subsequently washed extensively with HBSS. The infected monolayers of HET1-A cells were fixed in methanol and stained with crystal violet. The percentage of HET1-A cells with adhering yeast cells was determined by counting all HET1-A cells in four to five high-power fields. A positive was scored as one or more yeast cells per HET1-A cell. A total of at least 100 HET1-A cells was counted; adherence was expressed as the percentage of HET1-A cells with adhering yeast cell(s). The HBEC adherence assay was performed as previously described by Bailey et al. (1995). C. albicans cells $\left(2 \times 10^{7} \mathrm{ml}^{-1}\right)$ were incubated with HBEC $\left(1-2 \times 10^{5} \mathrm{ml}^{-1}\right)$ in $0 \cdot 2 \mathrm{M}$ PBS (pH 7.2) for $90 \mathrm{~min}$. Cultures were washed with sterile $0.2 \mathrm{M}$ PBS through filters with a pore size of $12.0 \mu \mathrm{m}$ (Nucleopore; PC), and the contents of the filter were transferred to microscope slides and stained with crystal violet to determine the percentage adherence. Adherence was expressed as the percentage of HBEC with adhering yeast cells. The MH-S (murine alveolar macrophage) adherence assay was performed using monolayers on glass coverslips as described above. MH-S cells were infected with approximately $1 \times 10^{7}$ yeast cells per coverslip. After a $90 \mathrm{~min}$ incubation at $37^{\circ} \mathrm{C}$, the coverslips were washed with HBSS and stained with the Gram stain. The percentage of MH-S cells with adhering yeast cells was determined as described above for the HET1-A cell adherence assays. All adherence assays were performed at $37{ }^{\circ} \mathrm{C}$ in an atmosphere of $5 \% \mathrm{CO}_{2}$. Adherence to HET1-A cells was also measured in the presence of the following sugars: D-galactose, D-glucose, L-fucose, $N$-acetyl-Dglucosamine, D-mannose and D-glucosamine, each at concentrations of $50-200 \mathrm{mM}$. Adherence was measured after a $90 \mathrm{~min}$ incubation as described above.

Scanning electron microscopy. Monolayers of HET1-A cells $\left(5 \times 10^{5}\right.$ cells per well) were prepared on $12 \mathrm{~mm}$ glass coverslips in tissue culture dishes ( $40 \mathrm{~mm}$; Nunc, VWR Scientific). The monolayers were infected as described above and after a $90 \mathrm{~min}$ incubation at $37^{\circ} \mathrm{C}$ the coverslips were removed, washed three times with PBS $(\mathrm{pH} 7.4)$, fixed in $1 \%(\mathrm{v} / \mathrm{v})$ paraformaldehyde $/ 3 \%(\mathrm{v} / \mathrm{v})$ glutaraldehyde for $20 \mathrm{~min}$, washed with PBS and post-fixed with $1 \%(\mathrm{v} / \mathrm{v})$ osmium tetroxide in PBS. Subsequently, the infected monolayers were washed with PBS, dehydrated with a graded series of acetones and subjected to critical point drying (Sanidri-780). The samples were then coated with platinum $(20 \mathrm{~nm})$ using a Hummer I sputter coater and viewed with a Hitachi 5570 scanning electron microscope.

Transmission electron microscopy. HET1-A cells $\left(5 \times 10^{5}\right.$ cells) were cultured in tissue culture Petri dishes ( $40 \mathrm{~mm}$; Nunc, VWR Scientific) containing $2 \mathrm{ml}$ EPM2 medium for $48 \mathrm{~h}$. Monolayers were washed with HBSS and infected with yeast cells as described above (see HET1-A adherence assay). After a 90 min incubation, non-adherent yeast cells were removed by washing monolayers three times with HBSS $(\mathrm{pH} 7 \cdot 2)$. Subsequently, infected monolayers were fixed with $2 \%$ glutaraldehyde in HBSS for $1 \mathrm{~h}$ at room temperature. The monolayers were washed three times with HBSS, post-fixed with $2 \%$ osmium tetroxide for $1 \mathrm{~h}$ at $4{ }^{\circ} \mathrm{C}$, and then dehydrated through a graded series of alcohols and embedded in situ with Epon (Ted Pella). Following polymerization of the Epon, the embedded monolayers were released from the tissue culture dishes by immersion in dry ice. Ultrathin sections were prepared, stained with lead citrate and examined using a JEOL $1200 \mathrm{X}$ transmission electron microscope.

Growth of $\boldsymbol{C}$. albicans in galactose or glucose. Yeast cells were grown overnight at $30^{\circ} \mathrm{C}$ in either YP-glucose or YPgalactose broth. Cells were washed with $0.2 \mathrm{M}$ PBS, pH $7 \cdot 2$, adjusted to a concentration of $6.3 \times 10^{7} \mathrm{cells} \mathrm{m}^{-1}$ and inoculated into $20 \mathrm{ml}$ of fresh YP broth containing either $500 \mathrm{mM} \mathrm{D}$ galactose or $500 \mathrm{mM}$-glucose to achieve a final concentration of $4 \times 10^{6}$ cells (ml YP broth) ${ }^{-1}$. Growth of cultures in YP- 
galactose or YP-glucose was measured turbidimetrically $(540 \mathrm{~nm})$ at various times using an LKB Ultrospec II spectrophotometer. Duplicate readings were obtained for each time interval.

SDSPAGE and immunoblotting. SDS-PAGE, under reducing conditions, and Western blotting were performed by previously established procedures (Wadsworth \& Calderone, 1993) using $\beta$-mercaptoethanol $(\beta$-ME) cell extracts as samples. Extraction of proteins from $C$. albicans YP cultures containing either $500 \mathrm{mM}$ D-galactose or D-glucose was done as described previously by Bailey et al. (1995). Equal amounts of proteins were separated on $10 \%(\mathrm{w} / \mathrm{v})$ gels and electrotransferred to nitrocellulose membranes $(0 \cdot 45 \mu \mathrm{m})$. Blots were stained with Aurodye or immunoblotted with rabbit polyclonal IgG antiwhole-C. albicans 4918 cells. For detection of immunoreactive proteins, anti-rabbit IgG-conjugated alkaline phosphatase was used as a secondary antibody, according to the manufacturer's protocol (Promega).

\section{RESULTS}

\section{Adherence of C. albicans to HET1-A cells}

We initially determined that following a 90 min incubation, approximately $11 \%$ of HET 1 -A cells had adhering Candida cells when the yeast cells were grown on YPglucose agar. Because the amount of HET1-A cells with adhering Candida cells seemed low, we examined the influence of other carbon sources in YP medium on the adherence of yeast cells to HET1-A cells. In addition to Dglucose, we performed preliminary experiments on the adherence of yeast cells grown in YP medium containing D-galactose, D-maltose, D-xylose or trehalose. Further, the concentration of sugars was increased in these experiments to $500 \mathrm{mM}$, since other investigators have shown that adherence of $C$. albicans yeast cells to acrylics or HBEC was greatest in media supplemented with $500 \mathrm{mM}$ D-galactose (McCourtie \& Douglas, 1981, 1984). Of the sugars tested, we found that the highest adherence occurred with D-galactose-grown cells (data not shown). Thus, in all subsequent experiments, we compared only Dgalactose- and D-glucose-grown organisms for their effects on adherence. We found that the adherence of $\mathrm{D}$ -

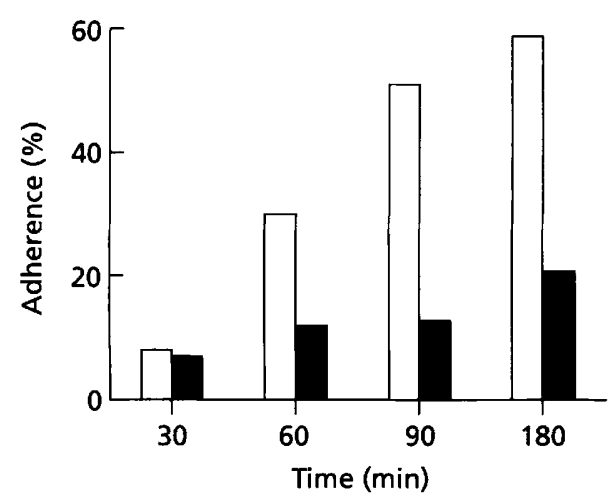

Fig. 1. Adherence of $C$. albicans yeast cells grown in YPgalactose (open bars) versus YP-glucose (filled bars) to HET1-A cells with time.
Table 1. Effect of galactose on the adherence of $C$. albicans to HET1-A, HBEC and MH-S cells

Yeast cells were obtained from either YP-glucose or YPgalactose medium and used to infect HET1-A, HBEC or MH-S cells. Incubation was performed at $37^{\circ} \mathrm{C}$ for $90 \mathrm{~min}$, infected cells were washed and adherence was measured by counting as described in the text.

\begin{tabular}{|llll|}
\hline & \multicolumn{3}{c|}{ Cells with adhering Candida (\%) } \\
\cline { 2 - 4 } & HET1-A & HBEC & MH-S \\
\hline Galactose & $31 \cdot 1 \pm 7 \cdot 0^{*}$ & $53 \pm 3$ & $49 \cdot 4 \pm 4$ \\
Glucose & $11 \cdot 7 \pm 4 \cdot 0$ & $25 \pm 5$ & $18 \cdot 1 \pm 1$ \\
\hline
\end{tabular}

* $P=0 \cdot 003$.

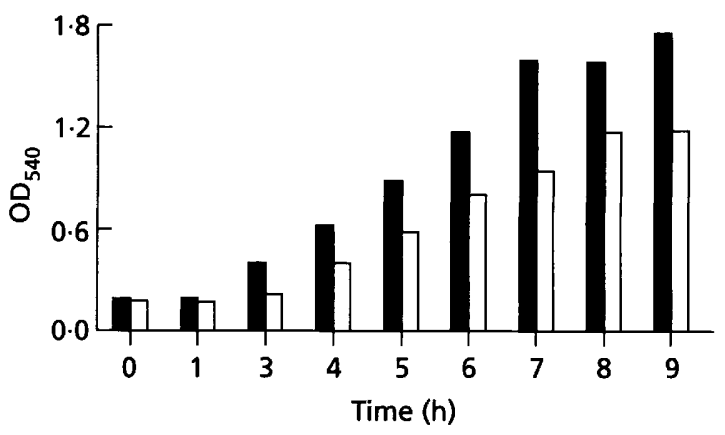

Fig. 2. Growth of C. albicans in YP-glucose (filled bars) versus YP-galactose (open bars) at $30^{\circ} \mathrm{C}$.

glucose-grown Candida to HET1-A cells was $11.6 \pm 2.5 \%$ and that of D-galactose-grown Candida was $30 \cdot 2 \pm 7 \cdot 9 \%$. The percentage of $C$. albicans inoculum which adhered to the HET1-A cells under optimum conditions was approximately $10 \%$. The adherence of the D-glucose- or D-galactose-grown organism to HET1-A cells was studied over time (Fig. 1). With D-galactose-grown cells, adherence increased from approximately $10 \%$ at $30 \mathrm{~min}$ to $60 \%$ after $180 \mathrm{~min}$. While the adherence at $90 \mathrm{~min}$ was not as great as at $180 \mathrm{~min}$, we chose to use a $90 \mathrm{~min}$ incubation for subsequent experiments, since plasticadherent yeast cells which had germinated tended to overgrow the HET1-A cells after a 90 min incubation.

In addition to the adherence studies with HET1-A cells, we measured the effect of galactose on the adherence of yeast cells to HBEC and a murine alveolar macrophage cell line (MH-S). These data are presented in Table 1. Adherence of yeast cells to HBEC and MH-S cells increased significantly when Candida was grown in YPgalactose compared to YP-glucose.

While D-galactose stimulated adherence of yeast cells, growth of $C$. albicans, as measured in YP-glucose broth at $30{ }^{\circ} \mathrm{C}$, was somewhat better than with cells grown in YPgalactose (Fig. 2). 
Table 2. Adherence of $C$. albicans to HET1-A cells: blocking experiments with sugars

Candida and HET1-A cells were incubated with sugar or buffer and adherence was measured after $90 \mathrm{~min}$. NAGA, N-Acetyl-Dglucosamine.

\begin{tabular}{|lcc|}
\hline Treatment & Adherence (\%) & $\begin{array}{c}\text { Inhibition of } \\
\text { adherence (\%) }\end{array}$ \\
\hline Buffer & $38 \cdot 8 \pm 8 \cdot 0$ & - \\
NAGA & $22 \cdot 5 \pm 1 \cdot 3$ & 40 \\
D-Glucosamine & $22 \cdot 8 \pm 5 \cdot 9$ & 40 \\
L-Fucose & $52 \cdot 0 \pm 11 \cdot 5$ & - \\
D-Glucose & $32 \cdot 0 \pm 4 \cdot 6$ & 20 \\
D-Galactose & $35 \cdot 7 \pm 4 \cdot 7$ & 10 \\
D-Mannose & $37 \cdot 5 \pm 3 \cdot 3$ & 3 \\
\hline
\end{tabular}

\section{Blocking experiments with sugars}

Adherence of $C$. albicans to HBEC can be blocked in the presence of L-fucose or amino sugars depending upon the strain of the organism used (Critchley \& Douglas, 1987b). We performed similar experiments by including $N$-acetylD-glucosamine, D-glucosamine, L-fucose, D-glucose, Dgalactose or D-mannose in the adherence assays. The data in Table 2 indicate that of the sugars listed above, $N$ acetyl-D-glucosamine or D-glucosamine inhibited the adherence of yeast cells to HET1-A cells by $40 \%$. LFucose, by comparison, stimulated adherence. Similarly to $C$. albicans 4918 , the adherence of other strains tested (A9 and 4918-2) was also inhibited by amino sugars (data not shown); however, L-fucose was not stimulatory as with strain 4918. In a separate experiment, we found that $\mathrm{N}$-acetyl-D-glucosamine or D-glucosamine blocked adherence when preincubated with Candida but not with the HET1-A cells (data not shown).

\section{Scanning and transmission electron microscopy}

Following incubation of the organism with HET1-A cells for $60 \mathrm{~min}$, we observed the adherence of yeast cells to HET1-A cells by light microscopy (Fig. 3a); additionally, the organism adhered to the tissue culture dishes in areas where HET1-A confluency had not occurred. Adhering yeast cells (to plastic or HET1-A cells) had germinated by $90 \mathrm{~min}$, although in many instances germination seemed to be somewhat inhibited when yeast cells adhered to HET1-A cells in comparison to plastic-adhered cells. We did not attempt to determine by light microscopy if the HET1-A cells phagocytosed C. albicans, and, instead, used scanning and transmission electron microscopy to characterize these events. By scanning electron microscopy (Fig. $3 \mathrm{~b}$ ), the organism was observed to germinate on the surface of the HET1-A cells. In some instances, the germ tube of the organism appeared to be within an infolding of the HET1-A membrane (Fig. 3b; see arrowhead), somewhat suggestive of a phagocytic process. HET1-A cell membrane ruffling at the point of contact with yeast cells and/or germ tubes was not observed. We also used transmission electron microscopy to characterize the Candida-HET1-A cell interaction. We observed the presence of HET1-A pseudopodia only at the yeast cellHET1-A cell junctions, again suggesting a phagocytic process (Fig. 3c; see arrowheads) or what appeared to be the beginning of a phagocytic event (Fig. 3d). Also, electron-dense material (of unknown origin) was often observed between closely associated HET1-A and Candida cells (data not shown). As stated previously, longer incubation times precluded microscopic analysis because of the overgrowth of plastic-attached, germinating yeast cells.

\section{SDSPAGE and Western blotting}

The protein profiles of the $\beta$-ME extracts from $\mathrm{D}$ galactose- or D-glucose-grown yeast cells are shown in Fig. 4. An array of proteins differing in molecular mass is revealed in Aurodye-stained blots. A protein of approximately $190 \mathrm{kDa}$ is observed only in the extract from Dgalactose-grown cells (Fig. 4, lanes 1 and 2 vs lane 3 ). Likewise, in Western blots, the $190 \mathrm{kDa}$ protein from Dgalactose-grown cells only was strongly immunoprecipitated by the anti-Candida rabbit IgG (Fig. 4, lane 4 vs lane 5). Other quantitative as well as qualitative differences between the two preparations were also observed.

\section{DISCUSSION}

Oral, oesophageal and/or vaginal candidiasis in AIDS patients is extremely common. While a number of studies of Candida-buccal or oral epithelial cell interactions have been reported (summarized by Calderone \& Wadsworth, 1993; Calderone \& Braun, 1991), there is little, if any, information on the adherence of the organism to human oesophageal epithelial cells. We used an SV-40-transformed human epithelial cell line (HET1-A) to study this interaction. The utility of the HET1-A cells is that they retain cell surface markers typical of epithelial cells and, thus, can be useful in characterizing the recognition system used by Candida.

We observed that maximal adherence of the organism was time-dependent and influenced by the carbon source used in preparing the yeast cells. The percentage of HET1-A cells with adhering Candida increased when the organism was grown in YP-galactose broth in comparison to YPglucose broth. Adherence was increased not only to HET1-A cells but also to HBEC and MH-S cells (a murine alveolar macrophage cell line). Our results with HBEC are similar to those described by McCourtie \& Douglas $(1981,1984)$. These authors observed that when grown in $500 \mathrm{mM}$ D-galactose, the cell surface of yeast cells assumed a pronounced fibrillar appearance not observed with cells grown in $50 \mathrm{mM}$ D-glucose. Interestingly, the galactose effect on adherence was only observed with strains of $C$. albicans from active infections. Strains from asymptomatic carriers did not exhibit the galactose-induced increase in adherence (McCourtie \& 

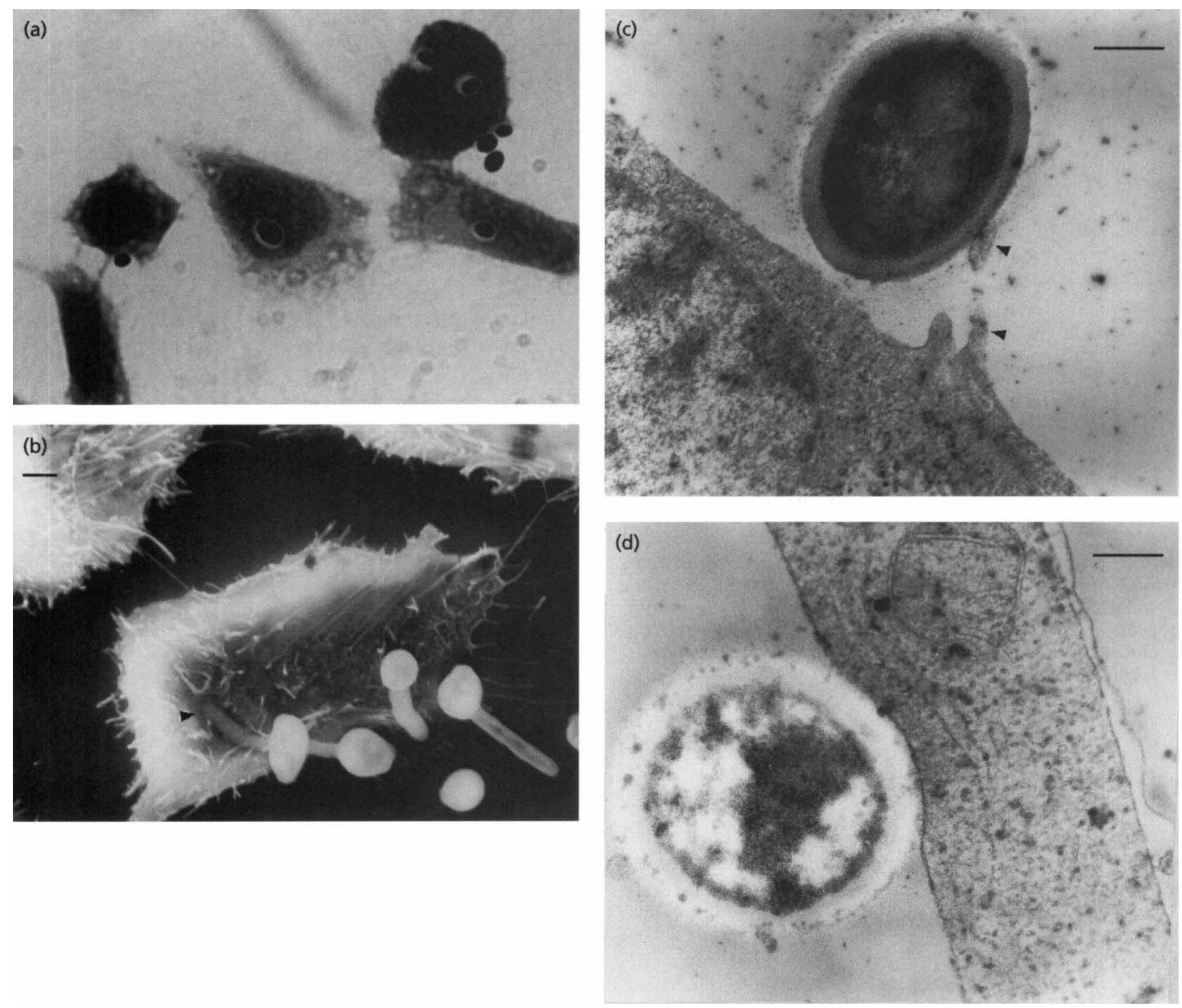

Fig. 3. Light and electron micrographs of HET1-A cells with yeast cells. (a) Adherence of yeast cells to HET1-A cells following a $60 \mathrm{~min}$ incubation as viewed by light microscopy. (b) Scanning electron microscopy of germinating yeast cells adhering to an HET1-A cell 90 min after infection. The germ tube appears to be within an HET1-A cell infolding (see arrowhead). Bar, $3 \mu \mathrm{m}$. (c) Transmission electron microscopy of adhering yeast cells. Note the pseudopodia-like structures associated with the HET1-A cells and extending to the yeast cell surface. Bar, $1 \mu \mathrm{m}$. (d) Apparent invagination of an HET1-A cell in close association with a C. albicans cell. Bar, $1 \mu \mathrm{m}$.

Douglas, 1984). Growth of the organism in D-galactose also resulted in an increase in mortality among infected animals when strains from active infections were used; in contrast, strains from asymptomatic carriers did not exhibit the augmented virulence when grown in galactose. While microscopic observations of the surface phenotype of cells grown in D-galactose were made, McCourtie \& Douglas (1984) did not determine if specific changes in cell wall protein profiles occurred in cells from the two different growth media. From culture supernatants of galactose-grown Candida, these investigators isolated an extracellular polymer which blocked the adherence of the organism to HBEC; also, the adherence of glucose-grown cells to acrylic increased when the acrylic was coated with extracellular polymer prepared from galactose-grown cells (McCourtie \& Douglas (1985).
In the present study, light microscopic observations of HET1-A-infected cells demonstrated that the organism adhered to and eventually germinated directly on the HET1-A cells. Plastic-adherent yeast cells also germinated even though monolayers were extensively washed with HBSS and all adherence assays were done in HBSS. Germination of $C$. albicans on plastic catheters in a nongerminating medium has been reported by Hawser \& Douglas (1994); our data would indicate a similar phenomenon.

Electron microscopic studies were done to characterize the Candida interaction with HET1-A cells. HET1-A cells formed pseudopodia-like structures when in close association with the organism, similar to the observation by Edwards et al. (1987) with human endothelial cells. 


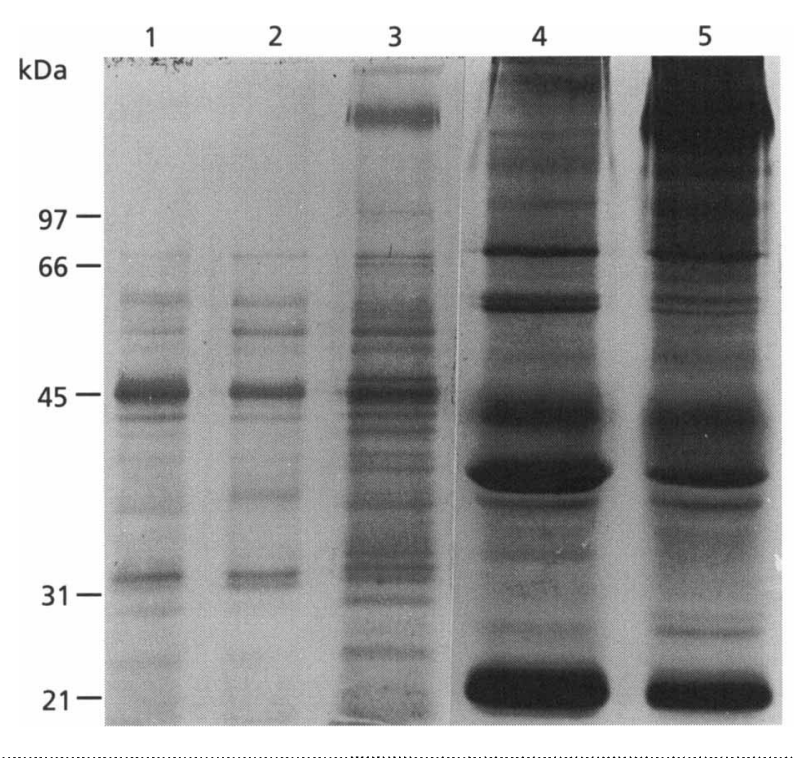

Fig. 4. SDS-PAGE and Western blot analyses of $\beta$-ME extracts from yeast cells grown in YP-glucose broth (lanes 1, 2 and 4) or in YP-galactose broth (lanes 3 and 5). Lanes: 1, 2 and 3, Aurodye stained; 4 and 5 , Western blot using purified IgG from a polyclonal antisera made in rabbits infected with $C$. albicans. Molecular mass standards are indicated.

The increased adherence of yeast cells grown in Dgalactose suggested the possibility that specific changes in the cell surface proteins may have occurred. Results from SDS-PAGE analyses verified this idea. A $190 \mathrm{kDa}$ protein present only in $\beta$-ME extracts from cultures grown in $\mathrm{D}$ galactose was observed. We are currently characterizing this protein to determine its role in adherence.

\section{ACKNOWLEDGEMENTS}

The authors wish to acknowledge that this work was supported by a US Public Health Service grant (NIH-NIAID PO1AI37251) to R.C. and by the Lombardi Cancer Research Center Cytochemistry and Morphology Core Facility, US PHS Grant 1P30-CA-51008. The authors also wish to thank Dr Curtis Harris, National Cancer Institute, for providing the HET1-A cell line and Dr K. Sankaran for providing the MH-S cells.

\section{REFERENCES}

Bailey, A., Wadsworth, E. \& Calderone, R. (1995). Adherence of Candida albicans to human buccal epithelial cells: host-induced protein synthesis and signaling events. Infect Immun 63, 569-572.

Calderone, R. A. \& Braun, P. (1991). Adherence and receptor relationships of Candida albicans. Microbiol Rev 55, 1-20.

Calderone, R. A. \& Wadsworth, E. (1993). Adherence molecules of Candida albicans. J Microbiol Methods 18, 197-211.

Calderone, R. A., Linehan, L., Wadsworth, E. \& Sandberg, A. (1988). Identification of C3d receptors on Candida albicans. Infect Immun 56, 252-258.

Critchley, I. A. \& Douglas, L. J. (1987a). Role of glycosides as epithelial cell receptors for Candida albicans. J Gen Microbiol 133, 637-643.
Critchley, I. A. \& Douglas, L. J. (1987b). Isolation and partial characterization of an adhesin from Candida albicans. J Gen Microbiol $133,629-636$.

Cutler, J. E. (1991). Putative virulence factors of Candida albicans. Annu Rev Microbiol 45, 187-218.

Edwards, J. E., Rotrosen, D., Fontaine, J. W., Haudenschild, C. C. \& Diamond, R. D. (1987). Neutrophil-mediated protection of cultured human vascular endothelial cells from damage by growing Candida albicans hyphae. Blood 69, 1450-1457.

Georgopapadakou, N. H. \& Walsh, T. J. (1994). Human mycoses: drugs and targets for emerging pathogens. Science 264, 371-373.

Hawser, S. P. \& Douglas, L. J. (1994). Biofilm formation by Candida species on the surface of catheter materials in vitro. Infect Immun 62, 915-921

Hoberg, K., Cihlar, R. \& Calderone, R. (1986). Characteristics of ccrulenin-resistant mutants of Candida albicans. Infect Immun 51, 102-109.

Klein, R. S., Harris, C. A., Small, C. B., Moll, B., Lesser, M. \& Friedland, G. H. (1984). Oral candidiasis in high-risk patients as the initial manifestation of acquired immunodeficiency syndrome. $N$ Engl J Med 311, 354-358.

Linehan, L., Wadsworth, E. \& Calderone, R. (1988). Candida albicans C3d receptor, isolated using a monoclonal antibody. Infect Immun 56, 1981-1986.

McCourtie, J. \& Douglas, L. J. (1981). Relationship between cell surface composition of Candida albicans and adherence to acrylic after growth on different carbon sources. Infect Immun 32, 1234-1241.

McCourtie, J. \& Douglas, L. J. (1984). Relationship between cell surface composition, adherence and virulence of Candida albicans. Infect Immun 45, 6-12.

McCourtie, J. \& Douglas, L. J. (1985). Extracellular polymer of Candida albicans: isolation, analysis and role in adhesion. $J$ Gen Microbiol 131, 495-503

Sankaran, K. \& Herscowitz, H. (1995). Phenotypic and functional heterogeneity of the murine alveolar macrophage-derived cell line MH-S. J Leukocyte Biol 57, 562-568.

Stoner, G. D., Kaighn, M. E., Reddel, R. R., Resau, J. H., Bowman, D., Naito, Z., Matsukura, N., You, M., Galati, A. J. \& Curtis, C. C. (1991). Establishment and characterization of SV-40 T-antigen immortalized human esophageal epithelial cells. Cancer Res 51, 365-371.

Tosh, F. D. \& Douglas, L. J. (1992). Characterization of a fucosebinding adhesin of Candida albicans. Infect Immun 60, 4734-4739.

Wadsworth, E. \& Calderone, R. A. (1993). Analysis of mannoproteins from blastoconidia and hyphae of Candida albicans with a common epitope recognized by anti-complement receptor type 2 antibodies. Infect Immun 61, 46754681.

Whelan, W. L., Delga, J. M., Wadsworth, E., Walsh, T. J., KwonChung, K. J., Calderone, R. A. \& Lipke, P. (1990). Isolation and characterization of cell surface mutants of Candida albicans. Infect Immun 58, 1552 1557 .

Yu, L., Lee, K. K., Sheth, H. B., Lane-Bell, P., Srivastava, G., Hindsgaul, O., Paranchych, W., Hodges, R. S. \& Irvin, R. T. (1994). Fimbria-mediated adherence of Candida albicans to glycosphingolipid receptors on human buccal epithelial cells. Infect Immun 62, $2843-2848$

Received 10 April 1996; revised 4 June 1996; accepted 4 June 1996 